\title{
Patients' Experiences of an Acceptance and Commitment Therapy-Based Approach for Psychosocial Difficulties Relating to an Appearance-Affecting Condition
}

\author{
Fabio A. Zucchelli ${ }^{1 *}$, Olivia Donnelly², Nick D Sharratt ${ }^{1}$, Nic Hooper ${ }^{3}$, Heidi M. Williamson ${ }^{1}$
}

\begin{abstract}
Some individuals with appearance-affecting conditions experience psychosocial challenges such as social anxiety and avoidance. Acceptance and Commitment Therapy (ACT) may offer a suitable approach for these challenges. This qualitative study investigated the lived experiences of patients with such appearance-related concerns, who had been through a one-to-one ACT-based intervention. It was expected that this would offer insights into the processes underpinning any positive impacts of therapy, potentially including ACT-specific elements. Semi-structured interviews were conducted with six female patients of a specialist clinical psychology service, where an appearance-focused ACT-based intervention was delivered. Participants described their experiences of therapy, any impact it had on their lives, and to what they attributed any changes. Interpretative Phenomenological Analysis, a qualitative method suited to exploring individuals' lived experiences, was used. Four superordinate themes included: Progress in body confidence, developing ways to take control over (re)action, developing acceptance of appearance, and compassion. These processes emanated from the participants' relationship with the treating psychologist, as well as specific skills used in sessions, and were enacted through participants' engagement in life-fulfilling activities. One-to-one ACT-based therapy appeared to help expedite the process of accepting a changed appearance, which participants highlighted as an important step in adjusting to their appearance. Participants' account of their improved body confidence can be understood in terms of an existing model of body image coping, offering a theoretical framework worthy of exploration in relation to ACT processes for this population. Participants' accounts also convey the centrality of therapists expressing compassion and helping patients to cultivate self-compassion.
\end{abstract}

\section{Keywords}

appearance, clinical health psychology, acceptance and commitment therapy, body image, interpretative phenomenological analysis (IPA)

${ }^{1}$ Centre for Appearance Research, University of the West of England Bristol, UK

${ }^{2}$ The Outlook Service, North Bristol NHS Trust, UK

${ }^{3}$ Psychology, Health and Social Sciences, University of the West of England Bristol, UK

*Corresponding author: fabio.zucchelli@uwe.ac.uk

\section{Introduction}

While many adjust well, some individuals with a visibly different appearance experience psychosocial challenges (Clarke, Thompson, Jenkinson, Rumsey, \& Newell, 2014; Moss \& Carr, 2004). Among some of the causes of differences in appearance are congenital conditions (e.g. birthmarks), medical conditions (e.g. psoriasis), injury (e.g. burn scarring) and medical treatment (e.g. surgery). Common difficulties in psychosocial adjustment have been identified across multiple appearance-affecting conditions. For example, in addition to perceived social stigmatisation and intrusive reactions from others such as staring, unsolicited comments and questions, individuals with appearance-affecting conditions often report marked preoccupation with their appearance, social anxiety and avoidance, self-stigma and poor body image (Rumsey, Clarke, White, Wyn-Williams, \& Garlick, 2004).

There is a recognised need to provide tailored, evidencebased counselling and therapy to help those with appearanceaffecting conditions manage the challenges they face (Harcourt et al., 2018), with some patients expressing a preference for one-to-one therapy over other modalities (Kleve \& Robinson, 1999; Richardson, Morton, \& Broadbent, 2015). Cosmetic or reconstructive interventions are limited in both their suitability and their impact on psychosocial adjustment across the range of appearance-affecting conditions; for ex- 
ample, a skin camouflage intervention for patients with skin blemishes did not improve fundamental aspects of appearance anxiety such as fear of negative evaluation (Kent \& Thompson, 2002). A hallmark of existing psychological interventions for this group, including Cognitive Behaviour Therapy (CBT), is graded exposure to feared social situations, buttressed by social skills training to manage negative reactions in public and/or social situations (Norman \& Moss, 2015). Researchers have examined one-to-one CBT-based interventions for adults with appearance-affecting conditions, finding generally positive preliminary evidence for improvements in psychological functioning (Bessell et al., 2012; Kleve, Rumsey, Wyn-Williams, \& White, 2002).

Acceptance and Commitment Therapy (ACT; Hayes, Pistorello, \& Levin, 2012) is a third-wave cognitive-behavioural approach that is also being used clinically by counselling and clinical psychologists across Europe to help those with appearance-affecting conditions (Harcourt et al., 2018; Stock, Zucchelli, Hudson, Kiff, \& Hammond, 2019). ACT is a transdiagnostic approach founded on behaviourist and functional contextualist principles that emphasise the unique role of the context or setting on behaviour, and the function that behaviour serves for the individual (Gifford \& Hayes, 1998; Törneke, 2010). ACT seeks to promote psychological flexibility, which refers to flexible behavioural regulation oriented by personally held values (Hayes et al., 2012). ACT's focus on the acceptance of internal events like thoughts and feelings, and values that extend beyond appearance concerns, makes it conceptually viable for this population (Zucchelli, Donnelly, Williamson, \& Hooper, 2018). Cross-sectional research also suggests that ACT constructs are associated with appearance-related distress and avoidance in the expected direction (Shepherd, Reynolds, Turner, O'Boyle, \& Thompson, 2019).

Although evidence has been steadily burgeoning for ACT in related domains of health psychology, including the selfmanagement of long-term conditions (Graham, Gouick, Krahe, \& Gillanders, 2016), no research has yet been published on the use of ACT for psychosocial difficulties relating to appearance-affecting conditions.

Additionally, research has yet to explore the lived experience of one-to-one psychological interventions (of any kind) for this population, using qualitative methods, which would offer a richer understanding of the processes that play out for patients. Qualitative methods have been employed to illuminate the complexities of issues pertaining to this group, including intimacy and romantic relationships in adults with a range of appearance-affecting conditions (Sharratt, Jenkinson, Moss, Clarke, \& Rumsey, 2018), psychological adjustment in alopecia (Welsh \& Guy, 2009), adult acne (Murray \& Rhodes, 2005) and vitiligo (Thompson, Kent, \& Smith, 2002), and body concealment in women following cancer treatment (Grogan, Mechan, Persson, Finlay, \& Hall, 2017).

\section{Aims of the Present Study}

This study aimed to understand how individuals with appearance-affecting conditions experience a one-to-one ACTbased intervention, and any impact it may have on their lives. The qualitative methods employed focus on the participants' lived experience. It was envisaged this would help refine the understanding of intrapersonal and interpersonal processes that this group may experience through the course of individual therapy, as well as the potential role of any ACT-specific processes.

\section{Method}

\section{Ethical Considerations}

The study was conducted in accordance with British Psychological Society ethical guidelines, including written informed consent. The study was approved by the university faculty research ethical committee (HAS.16.10.032) and local NHS Quality Assurance and Clinical Audit committee (CE76252). Interviews were audio-recorded and transcribed verbatim, with names replaced by pseudonyms and any identifying information removed.

\section{Methodology}

Interpretative phenomenological analysis (IPA) was considered the most suitable approach to address the study's aims, as IPA is predominantly designed to elucidate individuals' lived experience of significant phenomenon, which, in this study entailed going through ACT-based therapy and its impact on participants' lives. Participants' lived experience is explored in IPA by the researcher adopting the participants' perspective (the phenomenological aspect), while also presenting their own subjective interpretation, which may draw from relevant psychological theory such as the literature underlying ACT and the wider counselling psychology literature (the interpretative element; Smith \& Osborn, 2008). IPA has been used successfully to explore patients' experiences of appearance-affecting conditions (e.g.; Murray \& Rhodes, 2005; Thompson et al., 2002), as well as therapy patients' perceptions of their therapist (Bafiti, Viou, \& Tarasis, 2018). Qualitative studies of ACT interventions have also commonly employed IPA (e.g.; Mathias, Parry-Jones, \& Huws, 2014; Wardley, Flaxman, Willig, \& Gillanders, 2016).

\section{Intervention}

The intervention was provided at a specialist clinical health psychology service for appearance concerns based in a UK hospital. A consultant clinical psychologist experienced in ACT and in supporting people with appearance-affecting conditions (co-author on this article, henceforth referred to as 'the treating psychologist') delivered the intervention as part of their normal clinical practice. Individuals referred for appearance-related distress via numerous sources such as hospital outpatient departments and family doctors, were invited to an initial assessment, where they could discuss the background to their condition, current coping and impact (e.g. 
social anxiety, withdrawal), and their support goals. Where ACT was deemed appropriate, the psychologist explained the approach and gained informed consent for therapy.

The number of sessions offered was tailored to individual needs. A process-based ACT approach was used, based on a working therapeutic manual developed by the treating psychologist, with the core aim of increasing psychological flexibility and self-compassion. The process-based ACT approach allows the therapist to flexibly draw on the 'three pillars' of psychological flexibility emphasised in the manual: Be present, involving mindfulness skills and a sense of continuous self as distinct from one's internal experiences (self-as-context); open up, involving disentanglement with thoughts (cognitive defusion) and experiential acceptance (willingness); and do what matters, involving values clarification and values-based action. Therapy incorporated specific exercises and techniques tailored to the individual (e.g. mindfulness of the body, compassionate mirror use) and behavioural experiments in the form of willingness exposure tasks to help individuals draw on adaptive ways of coping when working towards valuesbased goals. Individuals completed weekly action plans based on the focus of each session, which were reviewed in the subsequent appointment. Specific themes tailored for the patient group were introduced as appropriate, such as managing intrusive comments and questions from other people, and acceptance of factors beyond one's control such as appearance, illustrated where appropriate through the serenity prayer (presented in a non-religious manner). This reads “... Grant me the serenity to accept the things I cannot change, courage to change the things I can, and wisdom to know the difference". Prior to the final session, individuals were asked to complete an end-of-therapy self-care plan. A three-month follow-up was offered.

\section{Participants}

Six women were recruited to this study and took part in semi-structured interviews following completion of at least eight ACT-based sessions. This sample size was selected due to the need in IPA to allow a substantial, time-consuming case-by-case analysis that fully explores each individual's account (Pietkiewicz \& Smith, 2014). Recommendations from clinical psychology doctoral programmes in the UK suggest between six and eight participants for IPA samples (Turpin et al., 1997). Purposive sampling was employed to recruit participants with a range of appearance-affecting conditions, in order to explore convergences in lived experience between conditions, as indicated by the research literature (Clarke et al., 2014). Individuals with appearance-affecting conditions who had been through at least eight ACT-based sessions at the specialist psychological service, were aged 18 or over and spoke fluent English were eligible to take part. Male gender was not an exclusion criterion, but no male patients emerged who met the inclusion criteria for this study. Participant characteristics are shown in Table 1. Participants' ages ranged from 18 years to 67 years. All identified as White British.

\section{Procedure}

Supervised by the fourth and fifth authors, the first author conducted interviews with participants, either in person at the specialist service, or by telephone, according to participants' preference. The interviews lasted between 30 and 72 minutes. The first author began with introductory questions about how participants came to access the service. These were followed by a set of overarching questions, adapted to participants' responses:

1. What was your overall experience of the sessions?

2. What impact, if any, have the sessions had on your life?

3. What do you put any changes down to? The first author also used "funneling questions", and prompts to explore specific issues (e.g. how participants experienced mindfulness training in daily life).

\section{Analysis}

Smith and Osborn's (2008) IPA guidelines were followed throughout analysis, moving from initial idiographic case-bycase theme production to between-case analyses. NVivo@ software was used to organise data. To ensure methodological rigour, the third and fifth co-authors reviewed the analysis process. The fifth co-author read a sample of three transcripts, to ensure the themes were grounded in the data. The treating psychologist was not involved in the analysis process, and instead contributed to the Discussion section.

\section{Positioning of the First Author}

The analysis of participants' experience presented in this article is necessarily intertwined with the first author's position within the sociocultural context (Smith \& Osborn, 2008). The first author is a male in his 30's who does not have an appearance-affecting condition, and has a long-standing positive personal experience of applying ACT principles. He kept a reflexivity log throughout the research process (e.g., Finlay, Peacock, \& Elander, 2018), to reflect on ways in which his personal experiences may have affected his interpretations of the data, as well as how his positioning may influence data collection in the interviews. For example, he noted his caution not to effuse partiality towards ACT practices during interviews, and that at times he was self-conscious of his gender:

When [participant] talked about aiming to wear a bikini at the beach, I felt very aware of my gender and again felt grateful that we were speaking over the phone rather than in person. Still wonder if she held anything back that she might have shared with a woman though?

The first author had no contact or relationship with any of the participants prior to inviting them to an interview for this study. 
Table 1

Participant Characteristics

\begin{tabular}{lcllll}
\hline Pseudonym & Age & $\begin{array}{l}\text { Appearance-affecting } \\
\text { condition }\end{array}$ & Appearance-related difficulties & $\begin{array}{l}\text { No. } \\
\text { of } \\
\text { sessions }\end{array}$ & $\begin{array}{l}\text { Interview } \\
\text { modality }\end{array}$ \\
\hline Maria & 39 & $\begin{array}{l}\text { Hair loss following medical } \\
\text { treatment on scalp }\end{array}$ & $\begin{array}{l}\text { Unable to leave home without hat; } \\
\text { Stopped working and socializing } \\
\text { Single mastectomy following } \\
\text { breast cancer }\end{array}$ & $\begin{array}{l}\text { Marked dissatisfaction with mul- } \\
\text { tiple reconstructive procedures; } \\
\text { Regular checking } \\
\text { Covered neck year-round; Social } \\
\text { withdrawal and anxiety }\end{array}$ & Face-to-face \\
Jane & 67 & $\begin{array}{l}\text { Keratosis (benign skin growths) } \\
\text { on neck }\end{array}$ & $\begin{array}{l}\text { Covered neck; Regular checking } \\
\text { Scarring following throat cancer } \\
\text { treatment }\end{array}$ & 9 & Telephone \\
Lucy & 18 & Widespread birthmarks & $\begin{array}{l}\text { Covered whole body year-round; } \\
\text { Feared attention from others } \\
\text { Social withdrawal and anxiety }\end{array}$ & 12 & Telephone \\
Harriet & 50 & Frontal fibrosing alopecia & Telephone \\
\hline Sam & 54 &
\end{tabular}

\section{Results}

The analysis procedure yielded four superordinate themes: (a) progress in body confidence; (b) developing ways to take control over (re)action; (c) developing acceptance of appearance; and (d) compassion. Other than the "developing acceptance of appearance" theme, each superordinate theme is split into subthemes. All themes are presented below with illustrative quotes.

\section{Progress in Body Confidence}

All participants described that through the course of therapy they had become more socially active, with their appearance more on display (which Harriet described collectively as "body confidence"). This superordinate theme attempts to capture the what, how and why of participants' experiences around body confidence.

\section{The 'What': Appearance Diminished as a Barrier}

All participants described how appearance, and especially their preoccupation with appearance, had presented a barrier to engaging fully in life before therapy. All mentioned that they were self-conscious about clothing. Some had endured physical discomfort in hot conditions, e.g. "[I] just sat there with a hat on and boiled to death" (Maria). In most cases, participants had avoided situations in which they feared others would judge their appearance. Harriet, who, at 18 years, was the youngest and the only participant with an altered appearance since birth, now felt largely free from appearance concerns:

So, do you mind me asking, from that original point [pre-therapy] when you were saying you used to always hide your birthmark and you hated people staring at you, where are you now? (First author) I'm really comfortable with my own clothes, just like around people I've never met before. Where they can see my birthmarks and everything. Like I'm not- I really don't mind now, I'll just do it. (Harriet)

Harriet's account conveyed a sense that therapy helped her progress with greater confidence into young adulthood. In contrast to Heather, all other participants had acquired an altered appearance as adults. Some reflected on how this had led to a sense of "a lost self", and a desire to recapture a former, perhaps even idealised self, less constrained by appearance concerns:

[treating psychologist and I] felt that the old [Sam] had gone. That's what I didn't like, I loved being the old [Sam]. And I felt that she had sort of disappeared, whereas I've been able to chip away at that a little bit now, and get- you know, it's never going to be totally the same, there's always going to be something. But I feel that I'm a bit better at allowing myself to be in [public] situations, whereas before I was putting a total block on them. (Sam)

Sam articulated a sense of her return to her former self as a work in progress. This ongoing effort was echoed by Jane:

I've worked with [treating psychologist] to try and get the confidence to wear less and not cover up so much. Um, I'm still struggling with that... I've left off the scarf quite a lot... I went up to club yesterday because I go to a club on Tuesday, slimming club, and I didn't wear a scarf or anything, and um, I was amongst a lot of people there, that I didn't uh [know]. Normally, I used to go away and [leave]. But I didn't. I've started staying... So that's better. (Jane) 
In contrast to Harriet, Jane still identified as being caught in a "struggle" with body confidence. Nonetheless, like most other participants, Jane emanated a sense of pride in the tangible progress she had made.

\section{The 'How': Graded Exposure Through Goal Setting}

Harriet implied a feeling of relief that, through therapy, she had finally received guidance on how to develop body confidence, following frustration from, and towards, her family "Before... [my family were] telling [me] that I should be confident rather than telling me how. [Treating psychologist] just helped, showed me some techniques to how, rather than just telling me I need to be." (Harriet)

Participants talked about how they had learned to apply techniques they had developed in therapy in challenging situations. The strategy that seemed to provide participants the clearest framework enabling progress in body confidence, was graded exposure to feared appearance-related situations and/or concealing less of their appearance. This was sometimes framed by collaboratively set goals and participants spoke of the importance of following manageable steps towards larger goals:

...we set goals, like really small goals, it was like a ladder... at the bottom it was just like "Wear a top that you could see a little bit of the top of it round my family", then it was round close friends, then it was do it at my boyfriend's house, and then it was like, just little things like tie your hair up, and then wear a top where you could see my birthmark with my hair up... And at the top it was wear your hair up, and go to the beach with a bikini on... the ladder really helped, that was like the pivotal thing. (Harriet)

\section{The 'Why': Deep Motivation}

Some participants revealed deeper motives for why therapy and working on their body confidence was worth undertaking, a cause for "determination" (a word used by half the group). Though not explicitly described as such by participants, these motives could be interpreted as representing participants' values. Some articulated motives explicitly, while for others they were implied. Three participants had children, and were driven to make positive changes in their lives by concerns about their welfare:

I didn't want to be limited to [not doing things]. And especially having a daughter who's only eleven. She wants to be out enjoying herself all the time, wants to go swimming, wants to be jumping out in puddles and off to festivals. You know, and I want to make sure I can do that. (Sam)

In her account, it seemed Sam needed the motivation of participating in her daughter's life to help drive her back into feared, but gratifying, social situations. Tacit in her account is her desire to also make sure her daughter could participate in all the activities she desired.

\section{Developing Ways to Take Control Over (Re)Action}

This superordinate theme covers participants' sense of feeling that through therapy they had gained greater control over their responses in challenging situations relating to appearance concerns, and, for some, in wider life domains like work and relationships.

\section{Responding to Unwanted Attention}

Most participants described having held fears about intrusive reactions from other people, like staring and unsolicited questions. Some recounted painful memories of such experiences. Having felt unprepared and unable to control previous encounters, these participants described working collaboratively in therapy to prepare responses, rehearse and regain control of social interactions:

... [treating psychologist] sort of helped me talk about how I could respond to people when they ask me about [my birthmarks], or if they're staring... I used to hate it when people stare at me. We sort of, sort of did like a role play sort of thing.(Harriet)

To some participants, such reactions, and especially questions about their appearance, didn't just highlight and exacerbate a sense of being conspicuous, but also the trauma of medical treatment. Maria's account reflects how participants conveyed a shift from feeling coerced into giving full answers to questions, to now having permission, via the treating psychologist, to give only the information they choose, and deflect attention:

... it was like: just say something simple and then pass the buck to them... it's knowing that it's ok to just say "Yeah, I've had an operation" [...] They say "What happened?" And you don't want to go through it all over again. Because every time you do you're re-living it really aren't you, and I think that drags you down really. So it would be "Oh yeah just had some surgery" or like if they've got children you can say "How's soand-so today?" or just a quick little answer and just kind of change it and then it's kind of swerving it isn't it... I wouldn't have really thought to do that before. (Maria)

\section{Reduced Emotional Reactivity Attributed to Mindfulness}

All participants described practicing mindfulness in some form, at least during the course of therapy if not at the time of interview. Some now perceived a greater ability to regulate their response to emotions (relating to their appearance concerns and beyond) when distressed, which they attributed to mindfulness practice: 
... with the issue of 'I don't look right, I don't feel right'- as a result of that or um, you know, I'm having a really bad time with somebody at work or, it's sending you on this emotional rollercoaster, but you have the tools to just take stock, um, just relax, calm, refocus your mind, let it go. [Mindfulness] is not a pill that fixes for a couple of weeks. It's something you just need to do quite a lot of. (Maria)

Maria's account alludes to a distinction between her initial emotional reaction as being under the control of uncontrollable forces, and a new-found level of control over the resulting emotional distress. Maria described applying mindful breathing techniques in-the-moment, and expressed pragmatic views about the need to maintain mindfulness practice for enduring effects. In contrast, Harriet described practicing mindfulness of breath around twice a week for 2 minutes at a time, yet still attributed this practice to dampened emotional reactivity:

I don't really use it that much in the situation. I just do it progressively and perpetually, because it just helps me stay calm. I've been getting less panicky I've noticed, I've noticed I'm not as panicky anymore, I just have a lot calmer reactions to things. (Harriet)

\section{Observing Thoughts as Thoughts}

Most participants described an empowering shift from having been "lost in thoughts" to "recognising the thoughts, that they are just thoughts" (Lucy), or cognitive defusion in ACT terms. Participants particularly embedded the passengers on a bus metaphor introduced in therapy (described by Rachel below) to real-life situations:

So I'm the driver of the bus and um all these thoughts are represented by individual people sat on the bus. So I can either take what they're saying on board and um let it affect me and let them drive my bus, or I can take it on board and go 'I'm just going to deal with that in a different way and I'm driving my bus'. So it was a bit more about me taking control, rather than letting others take control of me. (Rachel)

Maria, whose hair loss led to a fear of exposing her head to others, recounted applying the metaphor:

I was driving to the hairdressers and I just thought 'Oh, shall I bother going?' You know like, really, really strong like, 'Uh, I don't think I should do this'. But I just kept telling 'No, it's just passengers, it's ok- just keep going.' And I went and I had a really nice time. (Maria)
Here, in one brief recollection, Maria conveys perspectival agility in shifting between her sense as the agent of unhelpful thoughts, to recognising these thoughts as 'passengers' that just appear (cognitive defusion), and adopting a self-ascontext perspective (observing thoughts rather than being the thoughts).

\section{Reappraising Thoughts}

Though cognitive reappraisal is not a technique introduced in therapy, most participants seemed to organically make attempts to dispute unhelpful thoughts through the course of therapy, especially pertaining to other people paying attention and judging their appearance: "trying to teach yourself, 'Look, people aren't- they, they don't notice'. They're not looking at you" (Rachel). Participants found this helped them gain control when approaching feared social situations. For some participants, cognitive defusion appeared to lay the ground for cognitive reappraisal, by cultivating awareness of thoughts as they arise:

... going swimming. So, for the first time that was like, "I'm having the thought that people are going to be looking at me". But I went with my son's [swimming] group, and I just thought 'Do you know what, they're not going to be looking at me because they're going to be more focusing on their children, they're not going to even notice that I' $m$ in water and some of my hair's missing... (Maria)

Most participants talked about re-evaluating their appearance beliefs as a consequence of exposure to feared situations. When confronting such situations, participants seemed to be aided by a widening of their attention through the course of therapy (related to the open up component), which they described as having shifted from appearance-fixated and focused on others as a threat, to a more receptive, open attention, "just the way I feel towards people and like, I don't feel quite so defensive" (Lucy). Jane recalled an exposure exercise done in-session with the treating psychologist:

[Treating psychologist said] "Now will you walk out with me to the café?" "Yeah". So I went out walking with her and um... "How did you feel?" I said "Nobody was really- I mean I'm looking at them, they're not looking at me." (Jane)

\section{Developing Acceptance of Appearance}

This theme captures the message of accepting factors out of one's control conveyed in the (secularised) serenity prayer ('Grant me the serenity to accept the things I cannot change, courage to change the things I can, and wisdom to know the difference'), which was diffused throughout participants' accounts. Maria recalled the treating psychologist showing her the prayer, about which she said: "I just keep it up and I just look at it". 
Participants felt that their altered appearance was largely beyond medical control at the time of interview, and that an important process of therapy had been coming to terms with their appearance. For Rachel, following a series of breast reconstructive operations, this came as a shock in the early stages of therapy:

I needed to sort of come to terms with the fact that [the surgeon] wasn't going to do anything further, there was nothing he could do and that was that... my first session with um [treating pychologist] was um- and this is no reflection on her, but- it was very, very traumatic because I think um, I think she really hit the nail on the head. There was a bit of realisation about 'Ah shit you know, this is it.' (Rachel)

Sam still held hope for a medical "solution" to her alopecia, but had developed patience through greater acceptance of her situation in therapy:

I was just so desperate for somebody to say they have a solution for it all. And, like I say, didn't think talking to someone was going to be a solution... it's not solving the actual condition. [But] If I hadn't been speaking to [treating psychologist], I would be worried about where I am at this point because all of the time I'd have waited, over a year for a second referral... I think I would have got myself into quite a situation over it all. (Sam)

Jane raised this as an important process, but also one she continued to work on: "I've got to learn to live with and come to terms with [the skin growths] and get on with my life. Because it's not going to go... [It's] hard at times to accept it."

\section{Compassion}

Needing Compassion from the Therapist

The process of therapy was emotionally challenging for all participants, especially at the early stages. Participants felt that being given adequate time and space from a supportive person (the treating psychologist) "outside your family" (Jane) was crucial to their engagement in therapy. Jane's account reflected most participants' recollection that it had been difficult to express vulnerability in therapy:

... that's the hardest part of it, is to go in and try and open up and it's a very slow process and you hold back, you really hold back. You need, you need somebody there to be kind from the beginning and she was kind from beginning. (Jane)

\section{Gaining Permission to be Kind to Oneself}

Some participants expressed a self-critical disposition, and a sense of learning through therapy to adopt a self compassionate mindset. With this came a recurring feeling of gaining permission to be kinder to oneself, both explicitly guided by the treating psychologist and modelled by their compassion towards participants:

... being like nice to myself instead of being really horrible to yourself, because like she sort of like made me realise that, you know, the thoughts that you have about yourself, and I don't know but I know we all have them from time to timeif somebody else said that you, you'd probably want to get up and hit them [laughs]. But you know, you allow yourself to, to be really nasty to yourself... That was really important... (Lucy)

Here, Lucy's use of the third person points to an ingrained assumption that being unkind to oneself is normative, and a struggle of cultivating greater self-compassion. As part of this process, Lucy (and others) learned to reallocate their concern and compassion to themselves as well as others:

thinking of myself, of my own health, you know, rather than just thinking of others all the time. So that was another sort of little aspect that we worked on. (Lucy)

\section{Mindfulness as an Act of Self-Kindness}

Participants spoke of embedding formal mindfulness practice into their routine, although some wistfully reflected they had not maintained practice to the extent they had wished. Brief mindfulness practice, specifically following the sensations of breath, appeared to give participants a sense of respite from their daily hassles and responsibilities, a way of caring for themselves:

... a couple of times a week I sit on and have a half an hour train journey into work. And so it was all about allocating, being able to allocate that time to having a bit of brain stop and rest and doing this training. (Rachel)

\section{Discussion}

Participants' accounts offer insights into the interconnected aims of the study. In relation to the first aim of understanding participants' experiences of the one-to-one ACTbased intervention, their experiences were characterised by processes of internalising compassion and developing acceptance of their appearance. Both processes were testing for some of the group and drew on the strength of the therapeutic relationship. In terms of the second aim of understanding the impact of therapy on their lives, participants conveyed improved body confidence to different degrees. They also felt more control over their responses in appearance-related situations and beyond. 


\section{The Impact of Therapy}

Increased "confidence" was largely framed in terms of what this allowed participants to do, such as go out more in public situations, rather than how it may have reduced anxiety or other distress. This aligns with the ACT philosophy of focusing strategies like goal-setting and graded exposure on tailored behavioural outcomes aligned to patients' values rather than distress reduction, as is common in traditional CBT. For example, in Harriet's "ladder" of progressively challenging goals, each rung of the ladder was focused on allowing her to do more of what mattered to her. The treating psychologist did not ask Harriet to monitor her distress levels while carrying out the goals, with reduced distress used as a marker of progress. Regarding participants' motives for making positive changes, the "determination" participants spoke of from the start of therapy suggests each had entered therapy having reached a point at which they recognised their appearance concerns were substantially impacting their lives, equivalent to the preparation phase in the transtheoretical model of health behaviour change (Prochaska \& Velicer, 1997).

Participants' sense of being deeply motivated to make positive life changes by their love of their children chimes with research suggesting that meaning in life aids adaptation to profound physical changes (e.g., Psarra \& Kleftaras, 2013). Our construal of participants' motives as being based on their personal values (of the type taught in ACT) was only tentative, since participants did not talk overtly about their values. This may reflect the treating psychologist's practice as having focused less explicitly on values than presently, as they were was still refining their approach and the working therapeutic manual. This also points to the formative role patients have in continually developing therapists' and counsellors' practice (Rønnestad \& Skovholt, 2003) and how interview-based feedback, such as that gained from the present study, offers a valuable level of richness to stimulate therapists' reflective practice.

Alongside learning practical communication skills to deal with unwanted attention, participants attributed greater control in their emotional reactivity in difficult situations to brief mindfulness practice. Particularly striking was the benefit Harriet attributed to very short and intermittent mindfulness practices. It seems possible that other processes, like reduced perceived threat from other people as a result of graded exposure, may have also contributed to a calmer response. Equally, demand characteristics (Orne, 1962) may have influenced participants' attribution of positive outcomes to mindfulness practice. However, even brief mindfulness practices have been shown to activate neural pathways linked with the 'soothing' parasympathetic nervous system (e.g., Murakami et al., 2015), whereby perceived threats are down-regulated (Gilbert, 2015). This also relates to the additional function that mindfulness practice appeared to serve for participants, offering them a chance to periodically care for and soothe themselves.

Participants' reference to re-appraising their appearancerelated thoughts, especially regarding attention from other people, is interesting as it seemingly diverges from the ACT approach. However, while cognitive reappraisal was not targeted by the treating psychologist as a process of change, it is perhaps unsurprising that participants' thoughts organically changed. One of the contributory factors may be participants' greater capacity to "recognise thoughts... are just thoughts" (Lucy), or cognitive defusion. This process can be viewed through the lens of perspective-taking, an element of relational frame theory (RFT), a behavioural theory of human language rooted in functional contextualism underpinning ACT (Hayes, 2004). Relational frames describe the bidirectional relationships between verbal constructs, which according to RFT constitute the basis of all verbal thinking. Examples of relations relevant to cognitive fusion / defusion are temporal relations such as "Now" versus "Then", and spatial relations like "Here" and "There". When a participant has a thought like "People will stare at me", fusion with the thought entails the perspective "I-here-now". That is, they fully identify with the thought as a statement of reality in that moment, in that exact place. Taking such a thought as reality also gives it power to govern their behaviour, for example avoiding going out into public places (as in Sam's case pre-therapy). Through the process of learning to observe thoughts just as thoughts, for example through the Passengers on a Bus metaphor, participants may have learned to shift the context of a thought like "People will stare at me" to a perspective of "I-there-then". This means observing the thought they had as something "I thought there and then". This can help create psychological distance from the thought and reduce its ability to govern behaviour (Törneke, 2010). Participants also engaged in exposure tasks that, though focused on increasing life engagement, often also offered counter-evidence to their thoughts about being stared at or judged. This counter-evidence would have become more accessible to participants once they were less entangled in such threat-focused thoughts. Thought re-appraisal can therefore be understood as a by-product rather than deliberate process of change.

The process-based ACT paradigm that informed the therapists' approach centres around workability, the extent to which an individual's behaviour (mental or overt) serves their desired ends in the long-term (Hayes et al., 2012). For participants of this study, it appears disputing and reappraising their thoughts about other people's responses to their appearance proved workable. It should be acknowledged, though, that for some individuals with appearance-affecting conditions, thoughts about others paying attention to their appearance may be more realistic, and therefore less amenable to reappraisal. In such cases patients may be less likely to organically re-appraise their beliefs.

Participants' accounts of spontaneously reappraising thoughts relating to their appearance are in accordance with qualitative findings, whereby vitiligo patients reported organically using self-talk as a cognitive coping strategy (Thompson et al., 2002). Workability could also be seen in the same study, as participants also reported periodically resorting to other 
coping strategies such as avoidance or concealment, because cognitive strategies felt hard to sustain in all circumstances.

Taken together, participants' reports of their increased body confidence in relation to their starting point, and the ways in which they had taken control over their actions, appear to map onto Cash, Santos, and Williams's (2005) model of body image coping. This model proposes three predominant ways individuals cope with perceived threats to their body image. The first, and unhelpful coping strategy, involves avoiding and/or leaving situations that make appearance salient, such as Sam's prior avoidance or "total block" on public situations and Jane's previous tendency to leave slimming club prematurely. In a reversal of this unhelpful strategy, participants described increasingly engaging with appearanceexposing situations, such as Jane staying at slimming club for longer periods and Maria going to the hairdresser despite anxiety about her appearance. The second, and similarly unhelpful coping strategy, involves making attempts to cover, camouflage or change one's appearance, as in Maria's recollection of wearing a hat to conceal her hair loss even in hot conditions, and Jane's prior tendency to cover her neck with a scarf. Jane's account that since therapy "I've left off the scarf quite a lot" and Harriet's new-found confidence in wearing clothes that show her birthmarks even to new people suggest a similar shift away from this unhelpful coping strategy. Behavioural elements of therapy appeared to contribute to the reversing of both these unhelpful strategies, via goal-oriented graded exposure and skills practice for dealing with unwanted attention.

The third, more helpful approach, which can also be viewed as a means of reducing the two unhelpful coping strategies, is positive rational acceptance, which describes any strategy that contributes to an acceptance of the challenging situation and of one's appearance. This approach can be seen in participants' organic use of self-talk (e.g. Rachel and Maria's accounts of reappraising the likelihood of others noticing and judging their appearance), Lucy's description of learning to care for herself and her needs, and Rachel and Jane's growing acceptance of their appearance as being largely beyond the scope of medical intervention. Observing thoughts as thoughts (cognitive defusion) and reduced emotional reactivity from mindfulness practice offer additional strategies that may or may not be considered part of positive rational acceptance, depending on how the construct is interpreted. Cash et al.'s (2005) body image coping model has been examined in relation to ACT-based processes in the general population (e.g., Mancuso, 2016), but future research could explore the relationship between ACT processes such as cognitive defusion and these body image coping strategies in individuals with appearance-affecting conditions.

\section{Participants' Experience of Therapy}

The process of coming to accept their appearance voiced by participants likely reflects the treating psychologist's broad therapeutic approach drawn from experience of working with the patient population rather than purist ACT processes. While this type of situational acceptance is in principle entirely compatible with the ACT approach (given its aforementioned focus on workability), it is important to distinguish between the type of 'acceptance' specifically targeted in ACT, which refers to acceptance of internal experiences (e.g. thoughts, emotions, sensations), and acceptance of external factors such as one's appearance. Beyond the ACT approach, the theme of accepting one's appearance echoes the experiences recounted by alopecia patients, who described a natural transition from first coping by covering their hair, to eventually embodying acceptance and experiencing greater optimism about living with the condition (Welsh \& Guy, 2009). Findings from the present study suggest that one-to-one therapy may help expedite the acceptance process, which participants described as an important part of psychosocial adjustment, while also supporting previous research suggesting that this process can be challenging and fragile (Thompson et al., 2002).

It was clear from participants' accounts that self-compassion played a central role in supporting them through the early emotionally challenging stages of therapy, and gaining permission to be self-compassionate in their daily lives. Also clear was how participants absorbed this self-compassion from the treating psychologist.

\section{Implications for Counselling Psychology}

The therapist's stance, including embodying a sense of common humanity and compassion for the individual they are working with, is increasingly recognised as a foundational feature of ACT-based approaches (Luoma \& Platt, 2015). While ACT processes such as cognitive defusion, mindfulness and acceptance are arguably inherently self-compassionate, the findings support the assertion that a particular focus on self-compassion may benefit individuals with shame and selfstigma (common experiences in those with appearance-affecting conditions; Kent \& Thompson, 2002; Luoma \& Platt, 2015).

In broader therapeutic terms, recent research in the field of systemic psychotherapy has conceptualised participants' adoption of compassion from the therapist as a voice cultivated by the therapist, which requires rehearsal in therapy in order to being internalized by patients and ultimately expressed as self-compassion (Viou \& Georgaca, 2019).

The way in which participants favourably described working with the treating psychologist collaboratively on elements in therapy like goal setting and skills for dealing with unwanted attention is consistent with the wider counselling and psychotherapy literature. The importance of therapists working together with patients to agree on therapeutic goals and work towards them collaboratively has been recognised as an important common therapeutic factor across therapy models (Reisner, 2005). It is an approach entirely shared and endorsed by the ACT practitioner community (Plumb \& Vilardaga, 2010). 


\section{Limitations and Future Research}

While helpful in creating the sample homogeneity recommended for IPA, participants of this study were exclusively female, and hence the equivalent experiences of men remain unexplored. Similarly, only a small number of the many appearance-affecting conditions were represented, with only one participant having a condition from birth. Although an established body of literature shows commonalities in the experiences of people across a huge range of appearanceaffecting conditions (Clarke et al., 2014), nuances between the experiences of living with different conditions should also not be overlooked.

Participants were self-selected into this study and all reported positive experiences of therapy overall. We may therefore have missed the insights of individuals who had less favourable experiences. Lastly, this study interviewed patients of one treating psychologist in one specialist service. Attributes like rapport and communication style unique to the treating psychologist, and the physical environment unique to the service, should therefore be borne in mind when interpreting the results. The treating psychologists' ACT-based approach was also in a stage of development at the time of the participants accessing the service. Accordingly, the study was concerned with understanding participants' lived experiences of therapy, and drawing only tentative suggestions regarding the potential role of ACT processes, rather than evaluating ACT per se. Future research could more systematically test ACT for this patient group by conducting cross-centre multiple baseline studies, a useful methodology for specialist areas of clinical health psychology (e.g., Twohig \& Woods, 2004).

\section{Conclusions}

This qualitative interview study offers new insights into the experiences of female patients with appearance-affecting conditions going through one-to-one ACT-based therapy. In line with the ACT approach, participants' accounts suggest that new-found confidence in their appearance is characterised by engagement in life-fulfilling activities. Findings also indicate that individual therapy may have helped facilitate and accelerate a natural process for this population of accepting one's appearance, and that the therapist transmitting compassion is paramount to patients' continued therapeutic engagement and cultivation of self-compassion in daily life.

\section{Funding}

Data analysis and preparation of this manuscript was supported by a donation to the Centre for Appearance Research from the Vocational Training Charitable Trust (VTCT) Foundation.

\section{Conflict of Interest}

The authors declare that they have no competing interests.

\section{Acknowledgments}

The authors are grateful to the patients of the Outlook service at North Bristol NHS Trust for offering their time and hon- esty, the Outlook team and the NHS Trust for their support. The authors are also grateful for the support from the VTCT Foundation Research Team at the Centre for Appearance Research, UWE Bristol, comprised of Dr Amy Slater, Dr Heidi Williamson, Dr Nicola Marie Stock, Mr Nicholas D Sharratt, Mr Fabio Zucchelli, Ms Ella Guest, Ms Claire Hamlet, Ms Bruna Costa, Ms Jade Parnell, Ms Maia Thornton, Dr James Kiff, Professor Nichola Rumsey, and Professor Diana Harcourt.

\section{References}

Bafiti, T., Viou, M., \& Tarasis, P. (2018). "Stepping up the Ladder in Safety": An Interpretative Phenomenological Analysis of how LGB Clients Experience Their Therapists' Sexual Orientation. Euorpean Journal of Counselling Psychology, 7(1), 211-223. doi: 10.5964/ ejcop.v7i1.139

Bessell, A., Brough, V., Clarke, A., Harcourt, D., Moss, T., \& Rumsey, N. (2012). Evaluation of the effectiveness of Face IT, a computer-based psychosocial intervention for disfigurement-related distress. Psychology, Health \& Medicine, 17(5), 565-577. doi: 10.1080/13548506 .2011 .647701

Cash, T. F., Santos, M. T., \& Williams, E. F. (2005). Coping with body-image threats and challenges: Validation of the body image coping strategies inventory. Journal of Psychosomatic Research, 58(2), 190-199. doi: 10 .1016/j.jpsychores.2004.07.008

Clarke, A., Thompson, A. R., Jenkinson, E., Rumsey, N., \& Newell, R. (2014). CBT for appearance anxiety: Psychosocial interventions for anxiety due to visible difference. John Wiley \& Sons.

Finlay, K. A., Peacock, S., \& Elander, J. (2018). Developing successful social support: An Interpretative Phenomenological Analysis of mechanisms and processes in a chronic pain support group. Psychology \& Health, 33(7), 846-871. doi: 10.1080/08870446.2017 .1421188

Gifford, E. V., \& Hayes, S. C. (1998). Functional contextualism: A pragmatic philosophy for behavorial science. In W. O'Donohue \& R. Kitchener (Eds.), Handbook of Behavorism (p. 285-327). Academic Press.

Graham, C. D., Gouick, J., Krahe, C., \& Gillanders, D. (2016). A systematic review of the use of Acceptance and Commitment Therapy (ACT) in chronic disease and longterm conditions. Clinical Psychology Review, 46, 4658. doi: 10.1016/j.cpr.2016.04.009

Grogan, S., Mechan, J., Persson, S., Finlay, S., \& Hall, M. (2017). 'I've got a very dichotomous difference in the way that I perceive myself': Positive and negative constructions of body image following cancer treatment. Journal of Health Psychology, 24(10), 1368-1377. doi: 10.1177/1359105317730896

Harcourt, D., Hamlet, C., Feragen, K. B., Garcia-Lopez, L.J., Masnari, O., Mendes, J., ... others (2018). The 
provision of specialist psychosocial support for people with visible differences: A european survey. Body Image, 25, 35-39. doi: 10.1016/j.bodyim.2018.02.001

Hayes, S. C., Pistorello, J., \& Levin, M. E. (2012). Acceptance and Commitment Therapy as a unified model of behavior change. The Counseling Psychologist, 40(7), 976-1002. doi: 10.1177/0011000012460836

Kent, G., \& Thompson, A. (2002). The development and maintenance of shame in disfigurement. In P. Gilbert \& J. Miles (Eds.), Body shame: Conceptualisation, research and treatment (pp. 103-116). New York: Brunner-Routledge.

Kleve, L., \& Robinson, E. (1999). A survey of psychological need amongst adult burn-injured patients. Burns, 25(7), 575-579. doi: 10.1016/S0305-4179(99)00070-4

Kleve, L., Rumsey, N., Wyn-Williams, M., \& White, P. (2002). The effectiveness of cognitive-behavioural interventions provided at outlook: a disfigurement support unit. Journal of Evaluation in Clinical Practice, 8(4), 387395.

Luoma, J. B., \& Platt, M. G. (2015). Shame, self-criticism, self-stigma, and compassion in acceptance and commitment therapy. Current Opinion in Psychology, 2, 97-101. doi: 10.1016/j.copsyc.2014.12.016

Mancuso, S. G. (2016). Body image inflexibility mediates the relationship between body image evaluation and maladaptive body image coping strategies. Body Image, 16, 28-31. doi: 10.1016/j.bodyim.2015.10.003

Mathias, B., Parry-Jones, B., \& Huws, J. C. (2014). Individual experiences of an acceptance-based pain management programme: an interpretative phenomenological analysis. Psychology \& Health, 29(3), 279-296. doi: 10.1080/08870446.2013.845667

Moss, T., \& Carr, T. (2004). Understanding adjustment to disfigurement: the role of the self-concept. Psychology \& Health, 19(6), 737-748. doi: 10.1080/ 08870440410001722967

Murakami, H., Katsunuma, R., Oba, K., Terasawa, Y., Motomura, Y., Mishima, K., \& Moriguchi, Y. (2015). Neural networks for mindfulness and emotion suppression. PLoS One, 10(6), e0128005. doi: 10.1371/ journal.pone. 0128005

Murray, C. D., \& Rhodes, K. (2005). Nobody likes damaged goods: The experience of adult visible acne. British Journal of Health Psychology, 10(2), 183-202. doi: 10.1348/135910705X26128

Norman, A., \& Moss, T. P. (2015). Psychosocial interventions for adults with visible differences: a systematic review. PeerJ, 3, e870. doi: 10.7717/peerj.870

Orne, M. T. (1962). On the social psychology of the psychological experiment: With particular reference to demand characteristics and their implications. American Psychologist, 17(11), 776-783. doi: 10.1037/ h0043424

Pietkiewicz, I., \& Smith, J. A. (2014). A practical guide to using interpretative phenomenological analysis in qualitative research psychology. Psychological Journal, 20(1), 7-14. doi: 10.14691/cppj.20.1.7

Plumb, J. C., \& Vilardaga, R. (2010). Assessing treatment integrity in acceptance and commitment therapy: Strategies and suggestions. International Journal of Behavioral Consultation and Therapy, 6(3), 263-295. doi: 10.1037/h0100912

Prochaska, J. O., \& Velicer, W. F. (1997). The transtheoretical model of health behavior change. American Journal of Health Promotion, 12(1), 38-48. doi: 10.4278/0890 $-1171-12.1 .38$

Psarra, E., \& Kleftaras, G. (2013). Adaptation to physical disabilities: The role of meaning in life and depression. The European Journal of Counselling Psychology, 2(1), 79-99. doi: 10.5964/ejcop.v2i1.7

Reisner, A. D. (2005). The common factors, empirically validated treatments, and recovery models of therapeutic change. The Psychological Record, 55(3), 377-399. doi: 10.1007/BF03395517

Richardson, A. E., Morton, R., \& Broadbent, E. (2015). Psychological support needs of patients with head and neck cancer and their caregivers: A qualitative study. Psychology \& Health, 30(11), 1288-1305. doi: 10 $.1080 / 08870446.2015 .1045512$

Rønnestad, M. H., \& Skovholt, T. M. (2003). The journey of the counselor and therapist: Research findings and perspectives on professional development. Journal of Career Development, 30(1), 5-44. doi: 10.1177/089484530303000102

Rumsey, N., Clarke, A., White, P., Wyn-Williams, M., \& Garlick, W. (2004). Altered body image: appearancerelated concerns of people with visible disfigurement. Journal of Advanced Nursing, 48(5), 443-453. doi: 10.1111/j.1365-2648.2004.03227.x

Sharratt, N. D., Jenkinson, E., Moss, T., Clarke, A., \& Rumsey, N. (2018). Understandings and experiences of visible difference and romantic relationships: A qualitative exploration. Body Image, 27, 32-42. doi: 10.1016/ j.bodyim.2018.08.002

Shepherd, L., Reynolds, D. P., Turner, A., O’Boyle, C. P., \& Thompson, A. R. (2019). The role of psychological flexibility in appearance anxiety in people who have experienced a visible burn injury. Burns, 45(4), 942949. doi: 10.1016/j.burns.2018.11.015

Smith, J., \& Osborn, M. (2008). Interpretative phenomenological analysis. In J. Smith (Ed.), Qualitative psychology: A practical guide to research methods (p. 53-80). London: Sage.

Stock, N. M., Zucchelli, F., Hudson, N., Kiff, J. D., \& Hammond, V. (2019). Promoting psychosocial adjustment in individuals born with cleft lip and/or palate and their families: Current clinical practice in the United Kingdom. The Cleft Palate-Craniofacial Journal, 57(2), 186-197. doi: 10.1177/1055665619868331 
Thompson, A. R., Kent, G., \& Smith, J. A. (2002). Living with vitiligo: dealing with difference. British Journal of Health Psychology, 7(2), 213-225. doi: 10.1348/ 135910702169457

Turpin, G., Barley, V., Beail, N., Scaife, J., Slade, P., Smith, J. A., \& Walsh, S. (1997). Standards for research projects and theses involving qualitative methods: suggested guidelines for trainees and courses. Clinical Psychology Forum, 108, 3-7.

Twohig, M. P., \& Woods, D. W. (2004). A preliminary investigation of acceptance and commitment therapy and habit reversal as a treatment for trichotillomania. Behavior Therapy, 35(4), 803-820.

Törneke, N. (2010). Learning RFT: An introduction to relational frame theory and its clinical application. New Harbinger Publications.

Viou, M., \& Georgaca, E. (2019). Compassionate voices of clients and therapists in systemic group psychotherapy: A narrative study. Journal of Constructivist Psychology, 33(4), 433-440. doi: 10.1080/10720537.2019.1679302

Wardley, M. N., Flaxman, P. E., Willig, C., \& Gillanders, D. (2016). 'Feel the Feeling': Psychological practitioners' experience of Acceptance and Commitment Therapy well-being training in the workplace. Journal of Health Psychology, 21(8), 1536-1547. doi: $10.1177 / 1359105314557977$

Welsh, N., \& Guy, A. (2009). The lived experience of alopecia areata: A qualitative study. Body Image, 6(3), 194-200. doi: 10.1016/j.bodyim.2009.03.004

Zucchelli, F., Donnelly, O., Williamson, H., \& Hooper, N. (2018). Acceptance and Commitment Therapy for people experiencing appearance-related distress associated with a visible difference: a rationale and review of relevant research. Journal of Cognitive Psychotherapy, 32(3), 171-183. doi: 10.1891/0889-8391.32.3.171 